\title{
A Review of Localized Prostate Cancer: An African Perspective
}

\author{
Ayun Cassell ${ }^{\mathrm{a}, \mathrm{d}}$, Bashir Yunusa ${ }^{\mathrm{b}}$, Mohamed Jalloha ${ }^{\mathrm{a}}$, Mouhamadou M. Mbodji ${ }^{\mathrm{a}}$, \\ Abdourahmane Diallo ${ }^{a}$, Madina Ndoye ${ }^{a}$, Saint Charles Koukac, \\ Issa Labou ${ }^{\mathrm{a}}$, Lamine Nianga ${ }^{\mathrm{a}}$, Serigne M. Gueye ${ }^{\mathrm{a}}$
}

\begin{abstract}
Prostate cancer is the second most common malignancy in males and the sixth leading cause of cancer mortality in men with a relatively higher death rate in men of African descent. In the United States and other parts of Europe, more than $80 \%$ of diagnosed prostate cancer is localized, and $80-90 \%$ of these men receive some form of treatment. The projected data may not be a direct reflection of the disease in the sub-Saharan region as less than $40 \%$ presents with localized disease. Results from prostate cancer screening have shown that most African men in the sub-region have little knowledge of the disease. There are recommended international guidelines for the management of localized prostate cancer, however, a guideline in a local context could be ideal.
\end{abstract}

Keywords: Active surveillance; Localized prostate cancer; Prostate specific antigen; Radical prostatectomy

\section{Introduction}

Prostate cancer is the second most common malignancy in males, and approximately 1.1 million men globally were diagnosed in 2012 accounting for $15 \%$ of cancer in men [1]. Due to widespread prostate specific antigen (PSA) screening program and biopsy, the highest incidence of prostate cancer is seen in Australia/New Zealand and North America with a rate at (agestandardized rate (ASR) 111.6 and 97.2 per 100,000 respectively) and relatively high in less developed nations including the Caribbean (79.8/100,000), South Africa (61.7/100,000)

Manuscript submitted July 16, 2019, accepted July 30, 2019

aDepartment of Urology and Andrology, Hopital General de Grand Yoff, Dakar, Senegal

bDepartment of Surgery, Liberia College of Physicians and Surgeons, Monrovia, Liberia

'UFR Sante, Universite de Thies, Thies, Senegal

${ }^{\mathrm{d} C}$ Corresponding Author: Ayun Cassell, Department of Urology and Andrology, Hopital General de Grand Yoff, Dakar, Senegal.

Email: ayuncasselliii@gmail.com

doi: https://doi.org/10.14740/wjon1221 and South America $(60.1 / 100,000)$ [1].

Statistics from various African countries including Nigeria, Senegal, Gambia, Sierra Leone, Ivory Coast, Ghana, Cameroon and Angola have shown incidence rate lower to that of African American men [2]. In 2002, the age-standardized rate for prostate cancer in Nigeria (most populous African Nation) was estimated at 23.3/100,000 [2]. However, a prospective study by Osegbe et al [3] revealed a hospital-based incidence of 127 per 100,000 concluding that the incidence of prostate cancer in Nigerian men could be comparable to that of African American men (234.1 per 100,000) [2]. Prostate cancer is the sixth leading cause of cancer mortality in males with a relatively higher death rate in men of African descent (Caribbean, 29 per 100,000 and sub-Saharan Africa, ASRs $19-24$ per 100,000) [1].

Study by Rebbeck et al found that prostate cancer is a serious challenge in men of African descend and the actual incidence of prostate cancer is being underestimated in subSaharan settings due to lack of screening, lack of access to healthcare, genetics, lifestyle and environmental factors [4]. According to Jalloh et al, most of the health budget in sub-Saharan Africa is allocated to the management of tropical disease with little to no resource for cancer care [5]. Amidst these limitations, a lot of cases of prostate cancer remain undiagnosed or men with treatable localized disease could present with a much advanced stage of the disease.

In the United States and other parts of Europe, more than $80 \%$ of diagnosed prostate cancers are localized and $80-90 \%$ of these men receive some form of treatment. Some of these treatments will include active surveillance, radical prostatectomy or radiotherapy [6]. The American Urological Association (AUA), the European Urological Association (EAU) and the National Comprehensive Cancer Network (NCCN) have standardized guidelines for the management of localized prostate cancer. The management of localized prostate cancer in most part of sub-Saharan Africa is extrapolated from these guidelines. However, Prostate cancer care in the region is challenged by the late presentation making cure impossible, even though most men will die of other causes than their cancer. Reports from several prostate cancer screenings in Nigeria, Uganda and Senegal [7-9] have shown that most men in the survey had limited knowledge of prostate cancer symptoms and only a few had had previous serum PSA tested.

In most sub-Saharan nations, radical prostatectomy has been the gold standard for men with localized prostate cancer. 
Despite its cost effectiveness, it is still not accessible to patients who meet the indication due to lack of available expertise. Kyei et al [10] reported that in Ghana, men with localized prostate cancer are being managed with external beam radiation and brachytherapy. In 2006, a program to train urologist in Senegal and the sub-Saharan region to perform trans-perineal prostatectomy was initiated at the Hopital General de Grand Yoff published by (Ruenes and Gueye) [11].

The objective of this study is to review the epidemiological profile and treatment of localized prostate cancer in sub-Saharan Africa, and is a review of the current treatment guideline for localized disease.

\section{Literature Search}

The literature was from 1997 to 2018 using search engines PubMed, African Journal Online, Cochrane Library, and Google Scholar. The English literature was browsed using "Localized prostate Cancer" and appended as follow: America, Europe, Asia, sub-Saharan Africa, Senegal, Liberia, Ghana, Nigeria, Togo, Kenya, Tanzania and Uganda. The results of the search found 201 articles on localized prostate cancer. Only 31 publications were selected for the review including clinical guidelines, review articles, prospective and retrospective study. The clinical guidelines on prostate cancer included the AUA guideline, the EAU guideline and the NCCN guideline.

Both abstract and full text were reviewed for demographics, presentations, mean PSA, histological types, Gleason scores, treatment and outcomes. The results from the African literature were highlighted (Tables 1-3 [8, 10, 12-26]). A qualitative analysis of the data from African literature was performed and the discussion was enhanced using the available standard clinical guidelines. A quantitative pool analysis was performed using data (Tables 1, 2 [8, 10, 12-23]) from the study population, mean age, age range, PSA and elaborated in the main text of the results.

\section{Literature Retrieved}

Results from the literature search on prostate cancer in subSaharan Africa revealed that most of the studies are retrospective and non-randomized prospective studies (Table $1[8,10$, 12-23]). A pooled analysis of 1,997 men with prostate cancer reviewed above (Table 1 [8, 10, 12-23]) from Senegal, Nigeria, Togo, Burkina Faso, Kenya and Tanzania showed an age range of 30 to 100 years with a mean age of 67.7. Studies by Niang et al [24], Ndoye et al [13], Tengue et al [14], Kyei et al [10] Kabore et al [16, 18], Gueye et al [19] and Badmus et al [22] revealed lower urinary tract symptoms, suspicious digital rectal exam and elevated PSA as the commonest presentation which depicts that most men with prostate cancer in these regions present with locally advanced to advanced disease. Data by Ndoye et al [13] and Tengue et al [14] reported back pain and some neurological signs. These studies were almost uniquely patients with metastatic prostate cancer.

A pool analysis of the reviewed data (Table $2[8,10,12-$
16, 18-23]) showed very elevated PSA levels with a range of 0 to $21,660 \mathrm{ng} / \mathrm{mL}$ and mean PSA of approximately $438.9 \mathrm{ng} /$ $\mathrm{mL}$. However, reports by Kyei et al [10] and Babacar et al [21] had a study population of localized prostate cancer exclusively and reported a much lower mean PSA at 16.12 \pm 13.68 and 25 respectively. The predominant histological type in sub-Saharan nations is adenocarcinoma with a range of $95-100 \%$. A few variant histology squamous cell carcinoma [12], adenosquamous carcinoma [22] and embryonal rhabdomyosarcoma [23] were reported from Togo, Nigeria and Tanzania respectively (Table $2[8,10,12-16,18-23]$ ).

\section{Discussion}

The management of prostate cancer requires a multidisciplinary approach. However, guidelines of the AUA, the EAU and National Cancer Comprehensive Network recommend the management of prostate cancer based on risk stratification [27, 28]. Prostate cancer has been stratified into localized prostate cancer which could be very-low-risk, low-risk, intermediaterisk, and high-risk. To date this risk stratification poses great challenge in the management setting of prostate cancer in most developing nations. Due to the lack of well-structured prospective studies in sub-Saharan Africa, outcomes from radical prostatectomy, radiotherapy or hormonotherapy are not assessable and analyzable for guideline recommendations for organconfined prostate cancer. Moreover, $80-90 \%$ of prostate cancer in the developed countries presents as localized disease [29]; but this is far from being realistic in the sub-Saharan settings. A review of 13 studies from Nigeria, Ghana, Burkina, Togo, Senegal and Kenya (Table 3 [10, 14-22, 24-26]) has shown that a fewer percentage of men with prostate cancer present with localized disease ranging from $6.4-43 \%$ [10, 14-22, 2426].

Two studies from the region have reported exclusively on the management of localized prostate cancer. A prospective study by Kyei et al [10] from Ghana assessed the management and outcome of 20 patients who underwent radical prostatectomy; and a retrospective study by Babacar et al [21] from Senegal reviewed management of men with high-risk localized prostate cancer. The study population of both publications combined is minimum, so conclusions drawn from these reports remain underpowered. Therefore, the recommended treatment guideline of localized prostate cancer is summarized as follows to know where we are in Africa with the disease management. This should stimulate future practice-based, evidence-based guidelines in sub-Saharan Africa for organconfined prostate cancer.

\section{Very-low-risk prostate cancer}

Patients with very-low-risk prostate cancer are considered to have a PSA value $<10, \mathrm{~T} 1$ - T2a tumor, Gleason grade group $1,<34 \%$ of positive core on biopsy and a PSA density 0.15 $\mathrm{ng} / \mathrm{mL} / \mathrm{mm}^{3}$ [27]. There is enough evidence to suggest that patients with very-low-risk prostate cancer can be managed with 
Table 1. Demographics, Number of Patients and Presentation of Patients With Prostate Cancer in Sub-Saharan Africa

\begin{tabular}{|c|c|c|c|c|c|}
\hline Study & Study design & $\begin{array}{l}\text { Number of } \\
\text { patients }\end{array}$ & $\begin{array}{l}\text { Mean age } \\
\text { in years }\end{array}$ & $\begin{array}{l}\text { Age range } \\
\text { in years }\end{array}$ & Presentation \\
\hline $\begin{array}{l}\text { Niang et al } \\
\text { (Senegal) [8] }\end{array}$ & Retrospective study & 164 & 65 & $43-96$ & LUTS/suspicious DRE/elevated PSA \\
\hline $\begin{array}{l}\text { Ndoye et al } \\
\text { (Senegal) }[13]\end{array}$ & Retrospective study & 102 & $71 \pm 9$ & $51-96$ & Back pain/LUTS/suspicious DRE/neurological signs \\
\hline $\begin{array}{l}\text { Anunobi et al } \\
\text { (Nigeria) [15] }\end{array}$ & Retrospective study & 222 & 66 & $60-69$ & \\
\hline $\begin{array}{l}\text { Kyei et al } \\
\text { (Ghana) [10] }\end{array}$ & Prospective study & 20 & 62.7 & $51-72$ & LUTS \\
\hline $\begin{array}{l}\text { Kabore et al } \\
\text { (Burkina) [18] }\end{array}$ & Prospective study & 166 & 71.5 & $52-86$ & LUTS/suspicious DRE/elevated PSA \\
\hline $\begin{array}{l}\text { Gueye et al } \\
\text { (Senegal) [19] }\end{array}$ & Retrospective study & 121 & 69 & $52-88$ & LUTS \\
\hline $\begin{array}{l}\text { Obiorah et al } \\
\text { (Nigeria) [20] }\end{array}$ & Retrospective study & 198 & 70 & $42-90$ & \\
\hline $\begin{array}{l}\text { Babacar et al } \\
\text { (Senegal) [21] }\end{array}$ & Retrospective study & 35 & $63 \pm 5.9$ & $41-74$ & \\
\hline $\begin{array}{l}\text { Badmus et al } \\
\text { (Nigeria) [22] }\end{array}$ & Retrospective study & 189 & 68 & $40-100$ & LUTS/suspicious DRE \\
\hline
\end{tabular}

DRE: digital rectal exam; LUTS: lower urinary tract symptoms; PSA: prostate specific antigen.

Table 2. Mean PSA (ng/mL), the PSA Range as Well as the Histological Types

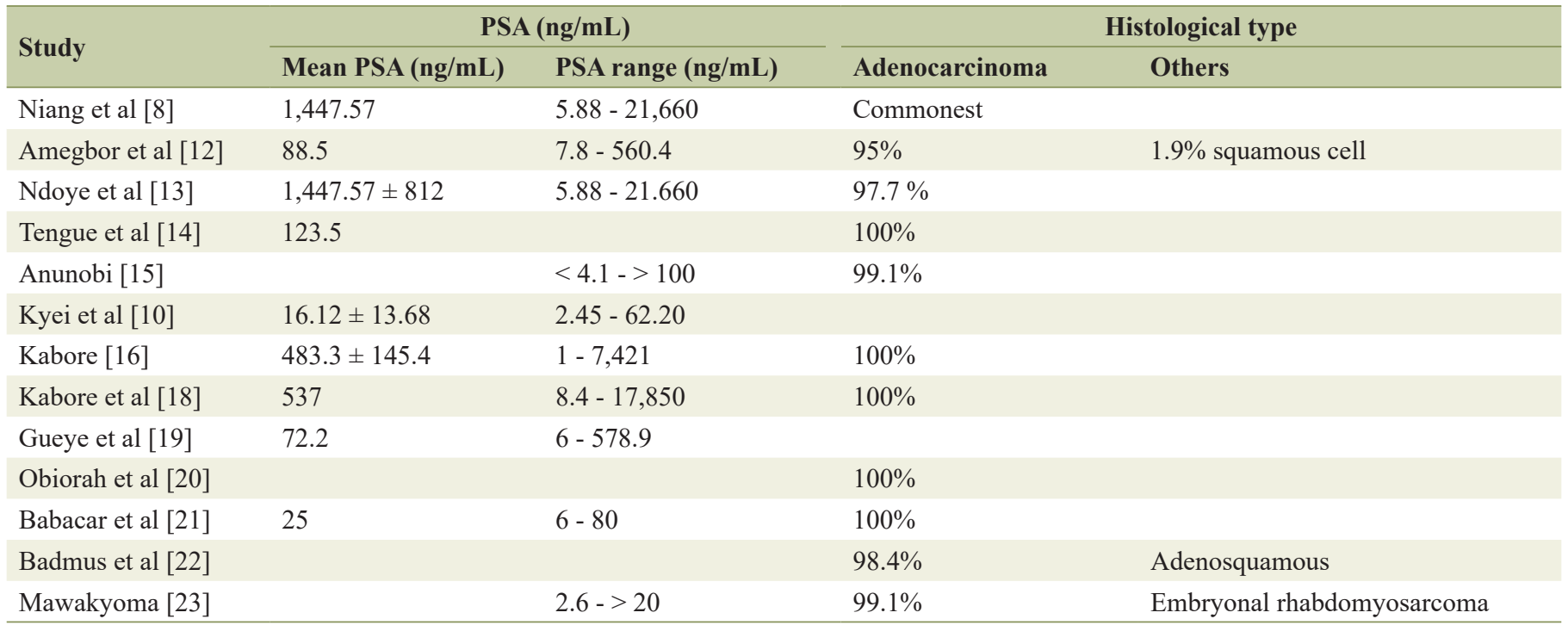

PSA: prostate specific antigen. 
Table 3. Few Sub-Saharan Studies Documented the Management of Localized Prostate Cancer

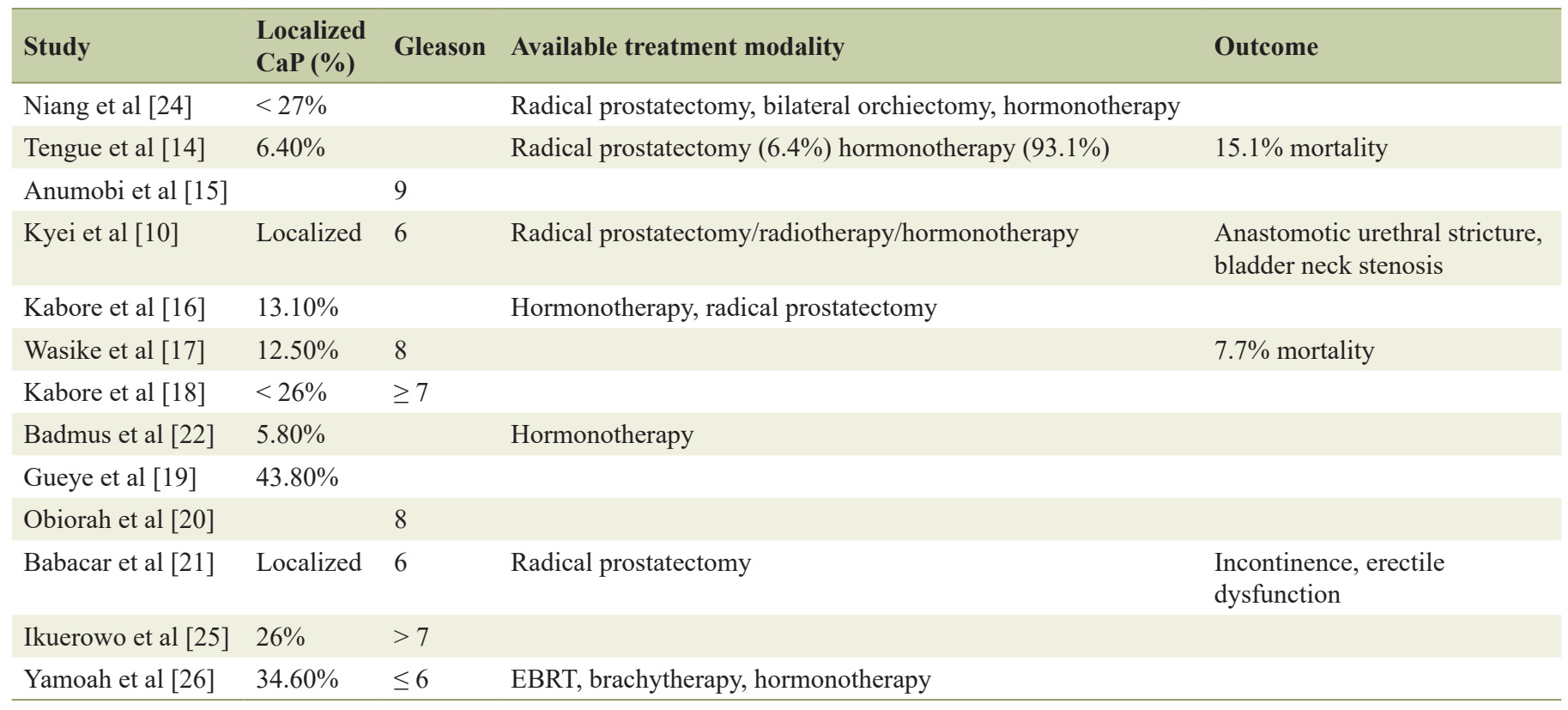

CaP: prostate cancer; EBRT: external beam radiation therapy.

active surveillance and computed tomography (CT) imaging is not recommended for staging. Data have shown that this subgroup has a 15-year metastatic progression rate of $<1 \%$ [27]. Active surveillance will require repeat biopsy at 3 years and 5 years after the confirmatory biopsy in this group. Men in this category preserve better continence as well as erectile function. There is subset of these patients that remain anxious with the knowledge of living with a cancer.

The true incidence of very-low-risk prostate cancer in the African population is unknown. Babacar et al from Senegal [21] reported T1 - T2a disease but their corresponding PSA levels, Gleason grade, percentage of positive core biopsy and PSA density were not available for prostate cancer risk stratification. However, most of the prostate cancers in the above study along with Yamoah et al [26] from Ghana were Gleason grade group 1 (Table 3 [10, 14-22, 24-26]).

\section{Low-risk prostate cancer}

According to the AUA guideline, the low-risk group includes men with PSA $<10 \mathrm{ng} / \mathrm{dL}, \mathrm{T} 1$ - T2a tumor, and Gleason grade group 1. CT imaging and bone scan are not required because they do not provide any useful management (changing information) in this group $[27,28]$. Active surveillance is recommended for low-risk patient regardless of the life expectancy. There is a modest risk of infection following prostate biopsy for active surveillance as well as missed occult tumor. However, there is low risk of metastasis progression in group on active surveillance making it acceptable compared to the much distressing complication of radical prostatectomy.

There are few selected patients with low-risk prostate cancer that should be considered for definitive therapy (radical prostatectomy or radiotherapy). Radiotherapy may be given as external beam radiotherapy or brachytherapy. Brachytherapy has similar side effects of erectile dysfunction and proctitis to external beam but presents with more urinary obstructive symptoms [27]. Men of African descent, obesity, systemic biopsy showing extensive Gleason scores or men reclassified as high risk after repeated biopsy should be candidates for cure by radiation or surgery. Studies have shown that about 3\% of this low risk will subsequently progress to metastatic disease [27]. Androgen deprivation therapy has shown no benefit in low-risk prostate cancer when given with radiotherapy. Whole gland cryosurgery and high-intensity focused ultrasound are available modalities, but patients must be counseled that these interventions do not offer benefit over standard treatment. Men presenting with life expectancy $<5$ years should be offered observation or watchful waiting with intent only to palliate their symptoms. This group will not require repeat biopsy as intervention does not improve overall survival over 5 years [27, 28].

There is sufficient evidence to suggest that active surveillance is feasible for indolent localized prostate cancer, but data have shown that black men do not show satisfactory outcomes with active surveillance compared to their white counterparts due to the aggressive nature of the disease in blacks [30]. A retrospective study of 379 Ghanaian men undergoing radiotherapy for prostate cancer revealed that $34.6 \%$ of patients with localized prostate cancer received either external beam radiation or brachytherapy [26]. The actual risk stratification for patients undergoing curative radiation therapy was not available in the data.

\section{Intermediate-risk prostate cancer}

Patients with intermediate-risk prostate cancer are divided 


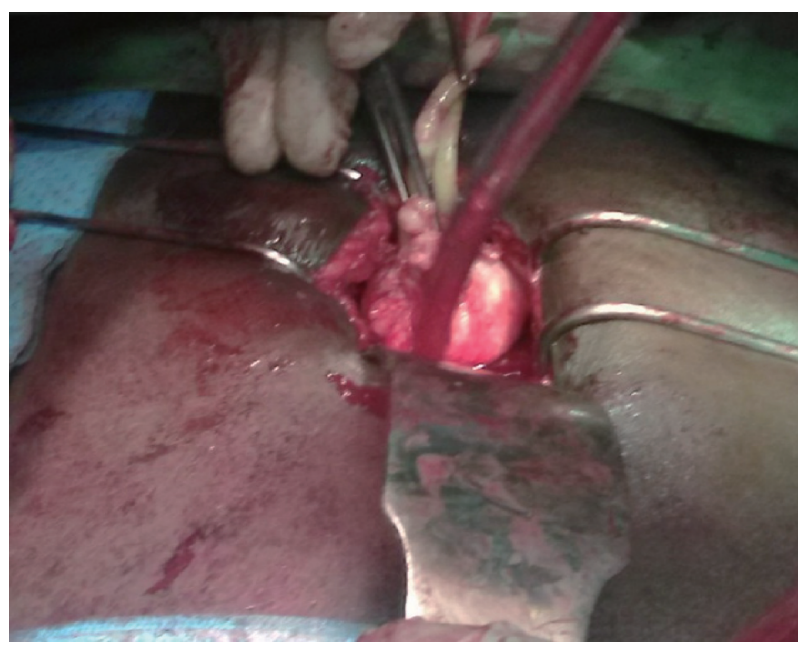

Figure 1. Retropubic radical prostatectomy and pelvic lymph node dissection for an unfavorable intermediate-risk T2b localized prostate cancer with Gleason grade group 3 and PSA of $15 \mathrm{ng} / \mathrm{dL}$ at the Hopital General de Grand Yoff, Dakar Senegal. PSA: prostate specific antigen.

into favorable intermediate-risk: (PSA 10 - 20) with Gleason grade group 1 or $(\mathrm{PSA}<10)$ with Gleason grade group 2 and unfavorable intermediate-risk: Gleason grade group 2 with either (PSA $10-20$ or clinical stage T2b-c) or Gleason grade group 3 with PSA $<20[27,28]$. Both the AUA guideline and the NCCN recommend cross sectional abdominopelvic imaging and bone scan in this group. Magnetic resonance imaging (MRI) has a better resolution for prostatic tissue than CT scan. Technetium bone scan are more feasible in clinical practice for prostate cancer though positron emission tomography/ computed tomography (PET/CT) may have a higher sensitivity $[27,28]$.

There is strong evidence to suggest that patients with intermediate risk should be considered for radical prostatectomy (Figs. 1, 2) or radiation therapy along with androgen therapy. A select few who are favorable intermediate risk who desire to preserve erectile function may be offered active surveillance or radiation alone $[27,28]$. However, these men should be well informed about the possibility of intervention in the future or cautioned against the much higher progression rate to metastasis. Those on active surveillance will require repeated digital rectal exam, systemic biopsy and PSA testing. Multiparametric MRI is now considered as a preferred imaging for patient's selection for active surveillance as it improves detection rate of occult disease $[27,28]$. Patients with life expectancy $<5$ years may be candidates for watchful waiting. These patients will not require repeated biopsy, PSA testing or any treatment intervention as the goal is to palliate symptoms [28]. Other treatment option including cryosurgery and high-intensity focused ultrasound lack evidence to be offered as standard treatment for intermediate-risk prostate cancer.

Though the data from the available African literature may be incomplete on risk stratification, it could be acknowledged that most of the men (Tables $2,3[8,10,12-26]$ ) may be moderate to high risk as reported in the studies from Nigeria, Kenya and Burkina Faso based on the elevated PSA and high

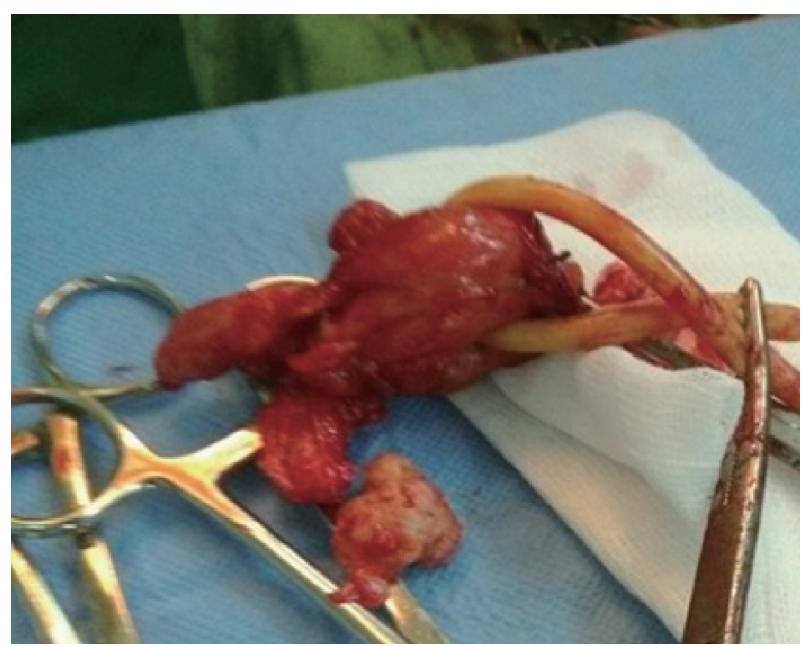

Figure 2. The postoperative prostate specimen en bloc with the seminal vesicles attached.

Gleason scores $[15,17,18,20,25]$ of $>7$. Radical prostatectomy which even though may be cost effective, is not readily available for most African men who meet the indication either due to technical nature of the procedure or due to the lack of access to health care and finance. Not many sub-Saharan publications report the management of localized prostate cancer specifically. However, two studies including one from Ghana and Senegal reviewed the outcome of radical prostatectomy in men with localized disease $[10,21]$.

\section{High-risk prostate}

High-risk localized prostate cancer is a life-threatening condition in men. According to the AUA guideline, high-risk disease is characterized by a PSA $>20 \mathrm{ng} / \mathrm{dL}$ or clinical stage $>\mathrm{T} 3$ or Gleason grade group 4 - 5 [27, 28]. A cross sectional staging CT scan or MRI along with a bone scan is recommended as the rate to metastatic progression is high. High-risk patients are not candidates for active surveillance and should be offered radical prostatectomy or radiation therapy with a longer course of androgen deprivation therapy about 24 to 36 months [27]. However limited evidences suggest that watchful waiting is possible for asymptomatic high-risk patient with life expectancy $<5$ years. Cryosurgery, high-intensity focused ultrasound and androgen deprivation as a monotherapy are not recommended in high-risk men. Men with high-risk localized prostate cancer with a strong family history of certain cancers should be sent for genetic counseling [27].

A study by Fall et al [31] in Senegal involving screening of 119 first-degree relative of patients with prostate cancer found that being black and having a familial risk factor did not appear to increase the incidence of prostate cancer. Rebbeck et al [4] hypothesized that lower rate of prostate cancer in sub-Saharan Africans compared to the higher rates in African Americans and Caribbean could be attributed to the lower genetic and environmental risk associated with sub-Saharan African men. 


\section{Outcome}

Data have shown that radical prostatectomy for localized highrisk prostate cancer has more survival benefit in the younger or healthier population than patients $>65$ years or with significant comorbidity. Robotic, laparoscopic and retropubic radical prostatectomy are reported to have similar postoperative outcomes when considering from erectile dysfunction and incontinence $[27,28]$. However, there is some data to prove that robotic-assisted or laparoscopic radical prostatectomy is associated with less perioperative blood loss than retropubic radical prostatectomy and a faster recovery from incontinence and erectile dysfunction [27]. Some men with localized highrisk disease would rather preserve sexual function. These patients can benefit from a nerve sparing radical prostatectomy, but the benefit of erectile function should be weighed against oncological outcomes. These men should be counseled that despite the preserved sexual function, ejaculation will not be achieved. A pelvic lymph node dissection should be done for all unfavorable intermediate-risk and high-risk group. Lymph node dissection includes the obturator, external and internal iliac nodes [27, 28].

A retrospective study in Senegal involving 35 men with high-risk organ-confined prostate cancer who underwent radical prostatectomy showed that incontinence and erectile dysfunction were the commonest postoperative complications [21]. Recurrence-free survival at 5 years was $70 \%$ and the overall survival at 6 years was $90 \%$.

\section{Post-treatment follow-up}

Since the goal of treatment of localized prostate cancer is cure, the PSA is monitored for progression over 10 years. Total remission is considered if PSA nadir remains below $0.2 \mathrm{ng} / \mathrm{dL}$ after radical prostatectomy or a PSA nadir below $2.0 \mathrm{ng} / \mathrm{dL}$ after radiotherapy \pm androgen deprivation therapy [27].

\section{Conclusions}

The management of prostate cancer remains a challenge in sub-Saharan Africa. Localized disease should theoretically have a better prognosis if the recommended guidelines are held. There is lack of complete data on the management of organ-confined prostate cancer amongst developing nations, and screenings have shown limited knowledge amongst African men with the disease. More institutional investment in prostate cancer screening, management and adherence to guideline could improve the outcome. Urologists in the sub-region need to publish their data of localized prostate cancer with risk stratification if possible. This would improve the assessment of intervention and outcome of the disease and treatment. Active surveillance, radical prostatectomy and to a lesser extend radiotherapy are all available to urologists in the sub-Saharan Africa and a regional guideline on localized prostate cancer is possible.

\section{Acknowledgments}

Special thanks to the Department of Urology and Andrology of the Hopital General de Grand Yoff.

\section{Conflict of Interest}

The authors declare no conflict of interest regarding this article.

\section{Financial Disclosure}

No external funding available to disclose.

\section{Author Contributions}

Conceptual design: AC, BY, MJ. Analysis, drafting and critical revision of the article: AC, BY, SK, AD, MM, and MN. Final approval of the article: AC, BY, MJ, AD, MM, MN, SK, LN, IL, and SG.

\section{References}

1. Ferlay J, Soerjomataram I, Dikshit R, Eser S, Mathers C, Rebelo M, Parkin DM, et al. Cancer incidence and mortality worldwide: sources, methods and major patterns in GLOBOCAN 2012. Int J Cancer. 2015;136(5):E359-386.

2. Odedina FT, Ogunbiyi JO, Ukoli FA. Roots of prostate cancer in African-American men. J Natl Med Assoc. 2006;98(4):539-543.

3. Osegbe DN. Prostate cancer in Nigerians: facts and nonfacts. J Urol. 1997;157(4):1340-1343.

4. Rebbeck TR, Devesa SS, Chang BL, Bunker CH, Cheng I, Cooney K, Eeles R, et al. Global patterns of prostate cancer incidence, aggressiveness, and mortality in men of african descent. Prostate Cancer. 2013;2013:560857.

5. Jalloh M, Niang L, Ndoye M, Labou I, Gueye SM. Prostate cancer in Sub Saharan Africa. J Nephr and Urol Res. 2013;1(1):15-20.

6. Oranusi CK, Mbieri UT, Oranusi IO, Nwofor AM. Prostate cancer awareness and screening among male public servants in Anambra State, Nigeria. Afr J Urol. 2012;18(2):72-74.

7. Nakandi H, Kirabo M, Semugabo C, Kittengo A, Kitayimbwa P, Kalungi S, Maena J. Knowledge, attitudes and practices of Ugandan men regarding prostate cancer. Afr J Urol. 2013;19(4):165-170.

8. Niang L, Kouka CN, Jalloh M, Gueye SM. Screening for Prostate Cancer by Digital Rectal Examination and PSA Determination in Senegal. ISRN Oncol. 2011;2011:943704.

9. McFall SL, Mullen PD, Byrd TL, Cantor SB, Le YC, Torres-Vigil I, Pettaway C, et al. Treatment decisions for localized prostate cancer: a concept mapping approach. 
Health Expect. 2015;18(6):2079-2090.

10. Kyei MY, Mensah EJ, Gepi-Attee S, Kwami D, Ampadu $\mathrm{K}$, Asante E, Klufio GO, et al. Outcomes after radical prostatectomy in Ghanaians: A surgeon's early experience. ISRN Urol. 2013;2013:832496.

11. Ruenes A, Jr., Gueye SM. Teaching radical prostatectomy in sub-Saharan Africa. Can J Urol. 2008;15(1):38863889.

12. Amegbor K, Seddoh TY, Tengue K, Songne-Gnamkoulamba B, Napo-Koura G, James K. Epidemiologie et histopronostic du cancer de la prostate au Togo: a propos de 202 cas diagnostiques au laboratoire d'anatomie pathologique du CHU Tokoin de Lome. Progres en urologie. 2009;19(2):112-115.

13. Ndoye M, Niang L, Gandaho KI, Jalloh M, Labou I, Gueye S. [Advanced prostate cancer in Senegal. Clinical aspects at the General Hospital of Grand Yoff]. Prog Urol. 2014;24(5):271-275.

14. Tengue K, Kpatcha TM, Botcho G, Leloua E, Amavi AK, Sikpa K, at al. Profil epidemiologique, diagnostique, therapeutique et evolutif du cancer de la prostate au Togo. Afr J Urol. 2016;22(2):76-82.

15. Anunobi CC, Akinde OR, Elesha SO, Daramola AO, Tijani KH, Ojewola RW. Prostate diseases in Lagos, Nigeria: a histologic study with tPSA correlation. Niger Postgrad Med J. 2011;18(2):98-104.

16. Kabore FA, Zango B, Kambou T, Ouedraogo AS, Bambara A, Yameogo C, at al. Prostate cancer disease characteristics at the time of diagnosis and initial treatment offered in a tertiary hospital at Ouagadougou (Burkina Faso). Open J Urol. 2014;4(01):7.

17. Wasike RW, Magoha GA. Descriptive case series of patients presenting with cancer of the prostate and their management at Kenyatta National Hospital, Nairobi. East African Med J. 2007;84(9):31-35.

18. Kabore FA, Zango B, Sanou A, Yameogo C, Kirakoya B. Prostate cancer outcome in Burkina Faso. Infect Agent Cancer. 2011;6(Suppl 2):S6.

19. Gueye SM, Jalloh M, Labou IE, Niang L, Kane R, Ndoye M. Profil clinique du cancer de la prostate au Senegal. Afr J Urol. 2004;10(3):203-207.

20. Obiorah CC, Nwosu SO. A histopathological study of carcinoma of the prostate in Port Harcourt, Nigeria. Niger J Clin Pract. 2011;14(3):363-367.
21. Babacar S, Aissatou BN, Cyrille ZO, Amath T, Alioune $\mathrm{S}$, Yaya $\mathrm{S}$ at al. Cancer de la prostate localise a haut risque de recidive: resultats de la prise charge. Afr J Urol. 2018;24(4):296-302.

22. Badmus TA, Adesunkanmi AR, Yusuf BM, Oseni GO, Eziyi AK, Bakare TI, Adetiloye JA, et al. Burden of prostate cancer in southwestern Nigeria. Urology. 2010;76(2):412-416.

23. Mawakyoma HA, Mabandi JL. Prostate cancer; Correlation of gleason's score and pretreatment prostate specific antigen in patients. Professional Med J. 2010;17(2):235240.

24. Niang L, Ndoye M, Ouattara A, Jalloh M, Labou M, Thiam I, Kouka SC, et al. [Management of prostate cancer in Senegal: what is being done?]. Prog Urol. 2013;23(1):3641.

25. Ikuerowo SO, Omisanjo OA, Bioku MJ, Ajala MO, Mordi VP, Esho JO. Prevalence and characteristics of prostate cancer among participants of a community-based screening in Nigeria using serum prostate specific antigen and digital rectal examination. Pan African Med J. 2013;15(1):1-6.

26. Yamoah K, Beecham K, Hegarty SE, Hyslop T, Showalter T, Yarney J. Early results of prostate cancer radiation therapy: an analysis with emphasis on research strategies to improve treatment delivery and outcomes. BMC Cancer. 2013;13:23.

27. Sanda MG, Chen RC, Crispino T, Freedland S, Nelson MD, Reston J, et al. Clinically localized prostate cancer: AUA/ASTRO/SUO guideline. Risk. 2017;6:27.

28. Heidenreich AP, Bastian PJ, Bellmunt J, Bolla M, Joniau $\mathrm{S}$, Mason MD, at al. Guidelines on prostate cancer. Eur Ass Urol. 2012:35-102.

29. Li J, Djenaba JA, Soman A, Rim SH, Master VA. Recent trends in prostate cancer incidence by age, cancer stage, and grade, the United States, 2001-2007. Prostate Cancer. 2012;2012:691380.

30. Persaud S, Goetz L, Burnett AL. Active surveillance for prostate cancer: Is it ready for primetime in the Caribbean? Afr J Urol. 2017;23(2):89-93.

31. Fall B, Sarr A, Ouedraogo B, Sow Y, Thiam A, Diallo $\mathrm{Y}$, et al. Detection precoce du cancer de la prostate chez des apparentes de premier degre au Senegal. Afr J Urol. 2015;21(4):225-229. 